\title{
CÂNCER DE PELE: UMA QUESTÃO DE SAÚDE PÚBLICA
}

\author{
SKIN CANCER: A PUBLIC HEALTH QUESTION
}

\section{Paula Francislaine MOURA ${ }^{1}$; Cristiane da Silva Paula OLIVEIRA ${ }^{2}$; Camila Freitas de OLIVEIRA ${ }^{3}$; Marilis Dallarmi MIGUEL ${ }^{4}$}

1- Farmacêutica - Mestre em Ciências Farmacêuticas - Universidade Federal do Paraná.

2- Farmacêutica - Doutora em Ciências Farmacêuticas - Universidade Federal do Paraná.

3- Farmacêutica - Mestre em Ciências Farmacêuticas - Universidade Federal do Paraná.

4 - Docente da Universidade Federal do Paraná.

Autor para correspondência: paulafrancislaine19@gmail.com

\section{RESUMO:}

Atualmente o câncer é uma doença com prevalência representativa no Brasil. Dos tipos de neoplasias, pode-se citar o câncer de pele que atinge em torno de $25 \%$ da população segundo dados do Instituto Nacional de Câncer José de Alencar Gomes da Silva (INCA). Devido à importância e abrangência dessa patologia são cada vez mais necessárias políticas públicas que assegurem o direito a saúde conquistado pela população com a criação do SUS que pode ser descrito como um sistema de saúde que articula município, estado e a federação para promoção e recuperação de saúde da população. O objetivo deste artigo foi realizar um levantamento bibliográfico sobre as políticas públicas de prevenção ao câncer de pele no SUS e legislações pertinentes. Foram pesquisados artigos que relatassem alguma intervenção que auxiliasse a população na prevenção desta patologia. Observou-se que ainda há uma grande escassez em políticas públicas voltadas especificamente para o câncer de pele, havendo um projeto de Lei que é amplamente citado porém que infelizmente não assegura a prevenção primária a esta patologia. Reforçando desta maneira a necessidade de mais pesquisas nessa área, para demonstrar a sua importância na atenção primária a saúde.

Palavras-chave: câncer de pele, prevenção, saúde pública.

\begin{abstract}
Currently cancer is a disease with a representative prevalence in Brazil. According to data from the National Cancer Institute José de Alencar Gomes da Silva (INCA), cancer of the skin accounts for around $25 \%$ of the population. Due to the importance and scope of this pathology, public policies are increasingly needed to ensure the right to health achieved by the population with the creation of SUS, which can be described as a health system that articulates the municipality, state and federation for the promotion and recovery of Health of the population. The objective of this article was to carry out a bibliographic survey about public policies for the prevention of skin cancer in the SUS and relevant legislation. We searched for articles that reported some intervention that would assist the population in the prevention of this pathology. It was observed that there is still a great shortage in public policies specifically focused on skin cancer, there is a bill that is widely cited but unfortunately does not ensure the primary prevention of this pathology. This reinforces the need for more research in this area to demonstrate its importance in primary health care. Keywords: skin cancer, prevention, public health.
\end{abstract}




\section{INTRODUÇÃO}

Câncer, por definição, é a denominação dada a um conjunto de mais de 100 patologias que tem como fator comum o crescimento celular descontrolado que são capazes de atingir tecidos e órgãos do corpo. Quando essas células são capazes de migrar para outras regiões do corpo diz-se que o câncer tem potencial de realizar metástase. Estas células tem o potencial de se dividir rapidamente formando tumores e não respondem a comandos celulares comuns do corpo humano em que essa patologia se encontra ausente. Pode-se dizer que o câncer maligno é agressivo às células do paciente, enquanto que o tumor dito benigno pode ser descrito como várias células com o crescimento lento e que se assemelham ao tecido onde estão localizadas, não representando, diferente dos tumores malignos, grande risco de vida. (INCA,2015a) ${ }^{1}$.

Fatores intrínsecos e externos ao organismo são descritas como causas do câncer. Como fatores intrínsecos pode-se citar o envelhecimento celular, danos no processo de divisão celular, entre outros. Como fatores externos pode-se citar hábitos de vida prejudiciais à saúde como tabagismo, exposição solar sem proteção, exposição à compostos químicos, dentre outros (INCA, 2015b) ${ }^{2}$. O surgimento dessa doença ocorre quando uma célula normal sofre alteração no DNA dos seus genes, essas células passam a não responder aos comandos do organismo, alterando assim sua atividade (INCA, $2015 c)^{3}$.

O câncer de pele é o mais prevalente do Brasil, representando $30 \%$ dos tumores malignos. É uma patologia mais prevalente em pessoas de pele clara e maiores de 40 anos, as quais são mais suscetíveis à ação nociva dos raios ultravioleta (UV), sendo que, pessoas com lesões prévias de pele tem ainda mais chance de desenvolver a doença. Outra característica importante é que este tipo de câncer é considerado raro em crianças e pessoas de pele negra (INCA, 2016) ${ }^{6}$.

Como fatores de risco pode-se citar a exposição da pele sem proteção à radiação UV, lesões crônicas de pele como úlceras e exposição a alguns componentes químicos como o arsênico. O câncer de pele é dividido em melanoma e não melanoma (INCA, 2002) 4 .

A neoplasia do tipo melanoma cutâneo tem como característica sua origem nos melanócitos, que são células produtoras de melanina. Tem sua prevalência em adultos brancos. Este tipo de câncer representa 3\% de malignidade e é considerado grave devido à sua grande possibilidade de metástase. Apesar destes fatores, o prognóstico desta patologia é considerado bom, se descoberto nos estágios iniciais da doença, sendo essa 
detecção precoce uma importante melhora na sobrevida do paciente. De acordo com o INCA a estimativa de novos casos para o ano de 2016 são de 5.670, sendo 3.000 homens e 2.670 mulheres e número de mortes de 1.547, sendo 903 homens e 644 mulheres (INCA, 2016) ${ }^{6}$.

O câncer não melanoma pode ser descrito como o mais frequente do Brasil, correspondendo a $30 \%$ dos tumores malignos no país. Apesar da sua maior incidência, apresenta menor taxa de mortalidade e altos casos de cura se detectado no estágio inicial. Essa neoplasia pode apresentar tumores de diferentes linhagens, devido a heterogeneidade da pele, sendo os mais prevalentes carcinoma basocelular (mais incidente e menos agressivo) e o carcinoma epidermoide. Quanto a estimativa de novos casos para 2016 o INCA contabilizou 175.760, sendo 80.850 homens e 94.910 mulheres, e número de mortes 1.769, sendo 1.000 homens e 769 mulheres (INCA, 2016) ${ }^{6}$.

Em 2010 o gasto do sistema público de saúde para o tratamento do câncer de pele no Brasil foi estimado em $\mathrm{R} \$ 37$ milhões, sendo que $95 \%$ dos casos foram diagnosticados precocemente (Souza et al, 2011).

O Decreto no 7.508 regulamenta a Lei orgânica da Saúde (Lei no 8.080 de 19 de setembro de 1990) e dispõe sobre a organização do SUS. Dessa maneira fica instituído na legislação brasileira o direito do paciente a ter acesso a saúde em todos os níveis de complexidade sendo que o sistema deve garantir promoção, proteção e recuperação da saúde de todos em território nacional (Decreto nำ 7.508, 2011)7.

Devida a grande importância, incidência e gastos desse tipo de patologia pode-se afirmar sua importância no campo da saúde pública e no âmbito do Sistema Único de Saúde (SUS) bem como a necessidade de sua prevenção, visto que essa ação melhoraria a saúde da população em geral, pela diminuição de casos e maior chance de cura, bem como a diminuição dos gastos nos diversos tratamentos aos quais o paciente deve ser submetido ao ter a doença. Desta maneira o presente artigo se justifica e tem por objetivo avaliar as políticas públicas de saúde voltadas a prevenção do câncer de pele no Brasil.

\section{METODOLOGIA}

O artigo utilizou como método a pesquisa bibliográfica de Leis e Decretos ainda vigentes em todo território nacional, bem como a pesquisa de dissertações, teses, artigos científicos já publicados e pesquisa no INCA, utilizando como parâmetro de inclusão informações científicas relacionadas a "câncer de pele", "tipos de câncer de pele", "O SUS 
e o câncer de pele", "gastos do Brasil com o câncer de pele" e "políticas públicas relacionadas a prevenção do câncer de pele".

\section{RESULTADOS E DISCUSSÃO}

Países tropicais apresentam alta exposição ao sol, além disso o Brasil apresenta diversidade de etnia, assim as pessoas de pele clara com a alta incidência de luz solar possuem maior prevalência de câncer de pele, indivíduos que apresentam exposição prolongada ao sol também fazem parte do grupo de risco como por exemplo marinheiros, agricultores carteiros, trabalhadores da construção civil (POPIM et al, 2008).

Com base na pesquisa realizada pode-se constatar que no Brasil tem-se em vigência várias legislações asseguradas pela constituição federal que instituem o direito da população à saúde em todos os seus níveis de complexidade. A Lei no 8.080 é um dos maiores exemplos que temos e uma das maiores conquistas do nosso sistema de saúde. Ela traz condições para a promoção, proteção e recuperação de saúde e a organização dos serviços. Desta maneira o SUS deve garantir todo tipo de tratamento aos pacientes e mais importante que isso promover a promoção à saúde, diminuindo dessa maneira gastos futuros no próprio sistema e garantindo qualidade de vida ao paciente. Estudos indicam que $80 \%$ dos problemas poderiam ser resolvidos com uma atenção básica bem estruturada e de qualidade, e a prevenção de muitas patologias também.

O câncer de pele devido a sua alta incidência e sua gravidade é um problema de saúde pública, porém na pesquisa realizada, não foram encontrados decretos ou leis pontuais para prevenção dessa doença. Um projeto de Lei amplamente visto nos artigos pesquisados como citado por ROSSO, 2010, é o de n 3730 de 2004 que dispõe sobre a obrigatoriedade de distribuição gratuita de protetor solar, pelo SUS. Esse projeto de Lei é importante devido ao fato de retratar a prevenção primária ao câncer de pele. O que ocorre, porém é a não aplicação dessa lei no sistema público.

A lei 4.027 de 2012 dispõe sobre o fornecimento de protetor solar ao empregado que trabalhe a céu aberto, como um equipamento de proteção individual (EPI), assegurando os profissionais que são expostos a radiação UV, deveriam obrigatoriamente receber o protetor solar do empregador, infelizmente essa lei muitas vezes é descumprida.

O estado do Rio grande do Sul se destacam na prevenção do câncer de pele, publicou a lei 13.676 de 2011 onde dispõe sobre a prevenção e combate ás doenças associadas a exposição solar do trabalhador rural, pescador e agricultor, onde estabelece 
ações voltadas para a prevenção e diagnóstico do câncer de pele, uma das ações visa a conscientização da população para o uso de protetores solares.

Desta maneira a prática infringe diretamente a seguridade de promoção e prevenção da saúde que consta em constituição federal, o que prejudica diretamente a saúde da população, visto que a exposição é inevitável. O tratamento na alta complexidade, consequentemente, leva a uma sobrecarga e um aumento de custos para o sistema que mais tarde e inevitavelmente terá de tratar esse paciente que poderia em muitos casos não ter desenvolvido essa patologia.

Outra questão importante é a qualidade de vida que o paciente deixa de ter. Sendo um tratamento com inúmeros efeitos colaterais que prejudicam a vida, rotina e causam sofrimento durante o tratamento. Além disso é um tratamento que pode apresentar longa duração e impacta economicamente e psicologicamente na vida da pessoa.

Toda essa complexidade poderia, porém ser minimizada por condutas simples como a distribuição do filtro solar, indicação do uso, educação em saúde e ênfase da importância do mesmo. Pois não basta apenas o sistema disponibilizar a prevenção sem realizar uma intensa conscientização na população. Outra conduta importante a ser empregada seria o esclarecimento sobre a neoplasia, enfatizando sua importância e seu diagnóstico precoce, para que as pessoas valorizassem essas informações e comunicassem ao médico possíveis sintomas que poderiam indicar a doença.

\section{CONCLUSÃo}

Frente a inúmeros problemas de saúde atuais as neoplasias podem ser citadas como complexas e de grande sofrimento ao paciente, além disso, os tratamentos apresentam um custo muito elevado e prognóstico ruim em caso de tumores com metástases.

Como maneira de prevenção e melhoria de qualidade de vida do paciente 0 Sistema Único de Saúde preconiza ações que muitas vezes não são cumpridas. Isso impacta diretamente no paciente que pode desenvolver uma patologia grave devido a uma falha na atenção primária.

Com esse artigo pode-se concluir que as políticas públicas que visam a prevenção do câncer de pele no Brasil devem ser aprimoradas, e que o sistema, deve-se se preocupar mais com prevenção e promoção de saúde dos seus pacientes. Apesar de diversos projetos de leis tramitarem entre os estados 
Sugere-se a realização de mais pesquisas neste campo e de uma maior preocupação das equipes multiprofissionais de saúde, bem como do Ministério da Saúde perante essa realidade.

\section{REFERÊNCIAS}

O que é o câncer? Instituto Nacional de Câncer José Alencar Gomes da Silva. Disponível em: http://www1.inca.gov.br/conteudo view.asp?id=322 Acesso em: 18/12/2015.

O que causa o câncer? Instituto Nacional de Câncer José Alencar Gomes da Silva. Disponível em: http://www1.inca.gov.br/conteudo view.asp?id=322 Acesso em: 18/12/2015.

Como surge o câncer? Instituto Nacional de Câncer José Alencar Gomes da Silva. Disponível em: http://www1.inca.gov.br/conteudo view.asp?id=322 Acesso em: 18/12/2015.

Instituto Nacional de Câncer José Alencar Gomes da Silva. Prevenção do câncer de pele. Prevenção e controle do câncer: normas e recomendações do INCA. Rev Bras Cancerol 2002;48(3):317-32.

Instituto Nacional de Câncer José Alencar Gomes da Silva. Pele Melanoma. Disponível em: http://www2.inca.gov.br/wps/wcm/connect/tiposdecancer/site/home/pele melanoma Acesso em: 04/01/2016.

Instituto Nacional de Câncer José Alencar Gomes da Silva. Pele não Melanoma. Disponível em: http://www2.inca.gov.br/wps/wcm/connect/tiposdecancer/site/home/pele nao melanoma Acesso em: 08/01/2016.

Brasil. Decreto no 7.508, de 28 de junho de 2011. Disponível em: http://www.planalto.gov.br/ccivil 03/ ato2011-2014/2011/decreto/D7508.htm Acesso em: 08/01/2016.

Brasil. Lei no 8.080, de 19 de setembro de 1990. Disponível em: http://www.planalto.gov.br/ccivil 03/Leis/L8080.htm Acesso em: 15/01/2016. 
BRASIL. Lei oํ 13.676, de 17 de Janeiro de 2011. Dispõe sobre a prevenção e o combate às doenças associadas à exposição solar do trabalhador rural e dá outras providências. Diário Oficial do Estado do Rio Grande do Sul, Porto Alegre RS.

Brasil. Projeto de Lei 3730 de 2004. Disponível em: http://www2.camara.leg.br/proposições Web/prop_mostrarintegra;jsessionid=3DD790DAF18F7F148CE74E853CDC4875. node2?codteor= 547609\&filename=Tramitacao-PL+3730/2004 Acesso em: 15/01/2016.

Rosso, A.C.C. O fornecimento do protetor solar como política pública de saúde na prevenção ao câncer de pele. Criciúma, junho de 2010.

Souza, R. J. S.; Mattedi, A. P.; Corrêa, M. P.; Rezende, M. I.; Ferreira, A. C. A.; Estimativa do custo do tratamento do câncer de pele tipo não-melanoma no Estado de São Paulo Brasil. An Bras Dermatol. 86(4): 657-52, 2011.

Popim, C. R.; Corrente, J. E.; Marino, J. A. G.; Souza, C. A. Skin cancer: use preventive measures and demographic profile of a rsik group in the city of Botucatu. Cienc. Saúde coletiva 13(4): 1331-1336, 2008. 